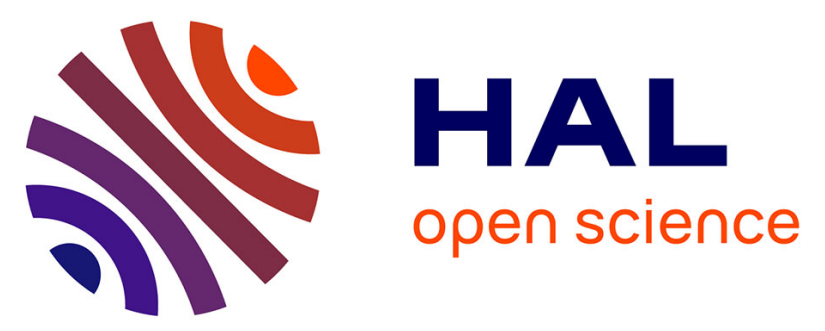

\title{
First evidence of correlation between Evapotranspiration and Gravity at a daily time scale from two vertically spaced superconducting gravimeters
}

Simon D. Carrière, Bertille Loiseau, Cédric Champollion, Chloé Ollivier, Nicolas K. Martin-st Paul, Nolwenn Lesparre, Albert Olioso, Jacques Hinderer, Damien Jougnot

\section{To cite this version:}

Simon D. Carrière, Bertille Loiseau, Cédric Champollion, Chloé Ollivier, Nicolas K. Martin-st Paul, et al.. First evidence of correlation between Evapotranspiration and Gravity at a daily time scale from two vertically spaced superconducting gravimeters. Geophysical Research Letters, 2021, 48 (24), pp.e2021GL096579. 10.1029/2021GL096579 . hal-03494887

\section{HAL Id: hal-03494887 \\ https://hal.science/hal-03494887}

Submitted on 20 Dec 2021

HAL is a multi-disciplinary open access archive for the deposit and dissemination of scientific research documents, whether they are published or not. The documents may come from teaching and research institutions in France or abroad, or from public or private research centers.
L'archive ouverte pluridisciplinaire HAL, est destinée au dépôt et à la diffusion de documents scientifiques de niveau recherche, publiés ou non, émanant des établissements d'enseignement et de recherche français ou étrangers, des laboratoires publics ou privés. 


\title{
First evidence of correlation between Evapotranspiration and Gravity at a daily time scale from two vertically spaced superconducting gravimeters
}

\author{
Simon D. Carrière ${ }^{1}$, Bertille Loiseau ${ }^{1}$, Cédric Champollion ${ }^{2}$, Chloé Ollivier ${ }^{3}$, Nicolas K. \\ Martin-StPaul $^{4}$, Nolwenn Lesparre ${ }^{5}$, Albert Olioso ${ }^{6}$, Jacques Hinderer ${ }^{5}$, Damien Jougnot ${ }^{1}$ \\ ${ }^{1}$ Sorbonne Université, UMR 7619 METIS (UPMC/CNRS/EPHE) 4 place Jussieu, 75005 Paris, France. \\ ${ }^{2}$ Université de Montpellier, UMR 5243 GM (CNRS/UM/UA), campus Triolet CC060, place Eugène Bataillon, \\ 34095 Montpellier cedex05, France. \\ ${ }^{3}$ IRD, UMR 5126 CESBIO (UPS/CNES/CNRS/INRAE/IRD), 18, Avenue Edouard Belin, 31401, Toulouse cedex 9, \\ France. \\ ${ }^{4}$ INRAE, URFM, Domaine Saint Paul, INRAE Centre de recherche PACA, 228 route de l'Aérodrome, CS 40509, \\ Domaine Saint-Paul, Site Agroparc, France. \\ ${ }^{5}$ CNRS, UMR 7063 ITES (US/ENGEES/CNRS), 1 Rue Blessig, 67084 Strasbourg, France. \\ ${ }^{6}$ INRAE, UMR 1114 EMMAH (AU/INRAE), Domaine Saint Paul, INRAE Centre de recherche PACA, 228 route de \\ l'Aérodrome, CS 40509, Domaine Saint-Paul, Site Agroparc, France.
}

Corresponding author: Simon D. Carrière (simon.carriere@upmc.fr)

This article was accepted in GEOPHYSICAL RESEARCH LETTER in December 2021: https://doi.org/10.1029/2021GL096579

Key Points:

- For the first time, two vertically spaced gravimeters allow to interpret small gravity hydrologically induced signal $\left(<5 \mathrm{~nm} / \mathrm{s}^{2}\right)$.

- Superconducting gravimetric signal are correlated with evapotranspiration at daily time step.

- Gravimetry enables an integrative estimate of evapotranspiration particularly relevant for hydrology 


\begin{abstract}
Estimating evapotranspiration (ET) is a primary challenge in modern hydrology. Hydrogravimetry is an integrative approach providing highly precise continuous measurement of gravity acceleration. However, large-scale effects (e.g., tides, polar motion, atmospheric loading) limit the fine time-scale interpretation of the gravity data and processing leads to residual signal noise. To circumvent this limitation, we exploited the difference between two superconducting gravimeters vertically spaced by $512 \mathrm{~m}$. The gravity difference allows to remove common large-scale effects. Daily variation of the gravity difference is significantly correlated with daily evapotranspiration as estimated using the water balance model SimpKcET $\left(\mathrm{p}\right.$-value $\left.=4 \cdot 10^{-10}\right)$. However, this approach is effective only during rain-free periods. In the future, comparison with direct ET measurements (e.g., eddy-covariance, scintillometer) may confirm and strengthen our interpretation. Improved hydrogravimetric data processing could extend the proposed approach to other experimental sites equipped with a single superconducting gravimeter.
\end{abstract}

\title{
Plain language Summary
}

Land evaporation and vegetation transpiration are crucial parameters in ecohydrology because evapotranspiration constitutes more than two-thirds of precipitated water at the continental scale. However, this invisible flux is difficult to characterize, especially at kilometric scale, and its quantification is challenging for the hydrologist community. Continuous gravity monitoring using a superconducting gravimeter is a direct estimation of the mass change of lands with high precision. At a mountain site in southern France, we highlight a significant association between evapotranspiration calculated by a numerical model and the mass loss of the mountain. This approach provides a novel way to monitor evapotranspiration that will reinforce traditionally used methods.

\section{Introduction}

Evapotranspiration (ET) is a key variable to understanding eco-hydrosystems because it links water, carbon, and energy cycles [Fisher, 2014]. ET is a major component of the water cycle, accounting for approximately $70 \%$ of precipitated water at the continental scale [Oki and Kanae, 2006; Fisher et al., 2017]. Several approaches exist for estimating ET, but large uncertainties persist and estimates remain difficult to validate, particularly at large scale [Verstraeten et al. 2008; Müller and Bolte 2009]. New approaches for estimating ET are crucially needed to improve our understanding of related processes.

Gravimetry is a geophysical method that measures the gravitational acceleration field $(g)$. During the last decades, progress has led to the development of devices that can now achieve precision of a few $\mathrm{nm} / \mathrm{s}^{2}$ and obtain highly accurate temporal monitoring [Van Camp et al. 2006]. These advances now allow to study the dynamics of ET. Data from the GRACE (Gravity Recovery and Climate Experiment) satellite have been used to study ET [Rodell et al. 2004; Long et al. 2014; Pan et al. 2017, Pascolini-Campbell et al. 2021]. The last studies have shown a correlation between GRACE data and regional-scale ET estimated by global models [e.g. Zhang et al. 2010; Mu et al. 
2011]. Superconducting gravimeter (SG) data are commonly used in hydrogravimetric studies that approach ET indirectly via water budgets [e.g. Hector et al. 2014; Fores et al. 2018; Chaffaut et al. 2021]. Only Van Camp et al. [2016] have directly interpreted the gravity signal as soil-toatmosphere water transfers at the daily time step. They found similar dynamics between the decreased signal of an underground SG (i.e., below the root levels) and decreased soil water content measured by TDR (time domain reflectometry) probes at 30, 45, and 60 centimeters. The relationship was observed in an oak and beech forest in Belgium on rain-free days. Direct comparison of ET to the gravity signal was not possible in Van Camp et al. [2016]'s study for two reasons: i) the daily water content change measured by TDR probes was not necessarily representative of ET at the plot scale, and ii) the limited signal to noise ratio constrained the authors to stack the signal over 10 days so as to limit perturbations. Indeed, Van Camp et al. [2016] discussed gravity signal processing difficulties in removing various perturbations: tidal effects, regional hydrological effects, atmospheric load, instrumental drift or even polar motion.

In this study, we broaden the approach: i) by working on the surface-to-depth difference between two vertically spaced superconducting gravimeters, one at the surface and the other at a depth of $512 \mathrm{~m}$. Such configuration allows to bypass signal processing issues by eliminating all common large-scale perturbations. ii) We consider local hydrological effects by using measured discharges at the outlet of the karst hydrosystem (Fontaine-de-Vaucluse spring). iii) We explore the direct link between the gravity signal and the daily ET dynamic calculated with the SimpKcET model validated on three (3) flux towers near the site [Ollivier et al. 2021]. For the first time, these conditions make it possible to relate gravity directly to ET signals at the daily time step.

\section{Materials and Methods}

\subsection{Site}

The experimental site is located in southern France $\left(43^{\circ} 56^{\prime} 28.7^{\prime \prime N}\right.$; 5 $\left.29^{\prime} 01.1^{\prime \prime E}\right)$ within the Fontaine-de-Vaucluse hydrosystem which covers $1200 \mathrm{~km}^{2}$. The site is part of the French critical zone observation network (OZCAR - http://www.ozcar-ri.org/). The karst hydrosystem is developed in Cretaceous limestones. The upper formations $(\approx 300 \mathrm{~m}$ thick; Fig. 1$)$ are lower Aptian / upper Barremian sub-reef limestones [Masse and Fenercci-Masse 2011] with high porosities (5$20 \%$ in the study area [Léonide et al. 2014]). Seasonal variations in water content, measured by MRS (magnetic resonance sounding), revealed the strong capacitive hydrogeological role of this limestone [Carrière et al. 2016; Mazzilli et al. 2020]. The underlying formations are lower Barremian limestones with significantly lower porosities (<5\% [Masse 1969; Guglielmi 2010]). This last formation has mainly a transmissive hydrogeological role.

Water discharge at Fontaine-de-Vaucluse spring is representative of the deep flow under the LSBB (Fig. 1C) for several reasons: i) soil and rock located between the two SGs (upper Barremian / lower Aptian limestones) have a strong capacity effect regarding water transfer due to high porosity [Carrière et al. 2016], ii) rocks located under the deep SG (lower Barremian limestones)

have only a transmissive role due to low porosity and high permeability through karst conduits, iii) the Fontaine-de-Vaucluse hydrosystem is a highly developed karst where water transfers within 
the saturated zone are very rapid (piston effect in a few hours) as demonstrated by Garry [2007] using an $\mathrm{Mg}^{2+}$ concentration time series analysis and Lesparre et al. [2017] using tiltmeter measurements, iv) Fontaine-de-Vaucluse discharge dynamics are similar to piezometric dynamics observed in a borehole near the site LSBB.

The topography of the study area is a southward slope. The elevation ranges between 500 and 1100 m.a.s.l. whereas the top of the saturated zone within the karst is at approximately 100 m.a.s.l. (Fig. 1). The thick vadose zone made it possible to excavate a tunnel $3.8 \mathrm{~km}$ long with a depth ranging between 0 and $512 \mathrm{~m} \mathrm{~mm}$ deep. This structure was a military bunker converted into a scientific research laboratory named "LSBB" in 1997 (http://lsbb.eu/presentation/). This underground facility cuts through the limestone and provides unique access to the karst unsaturated zone (Fig. 1).

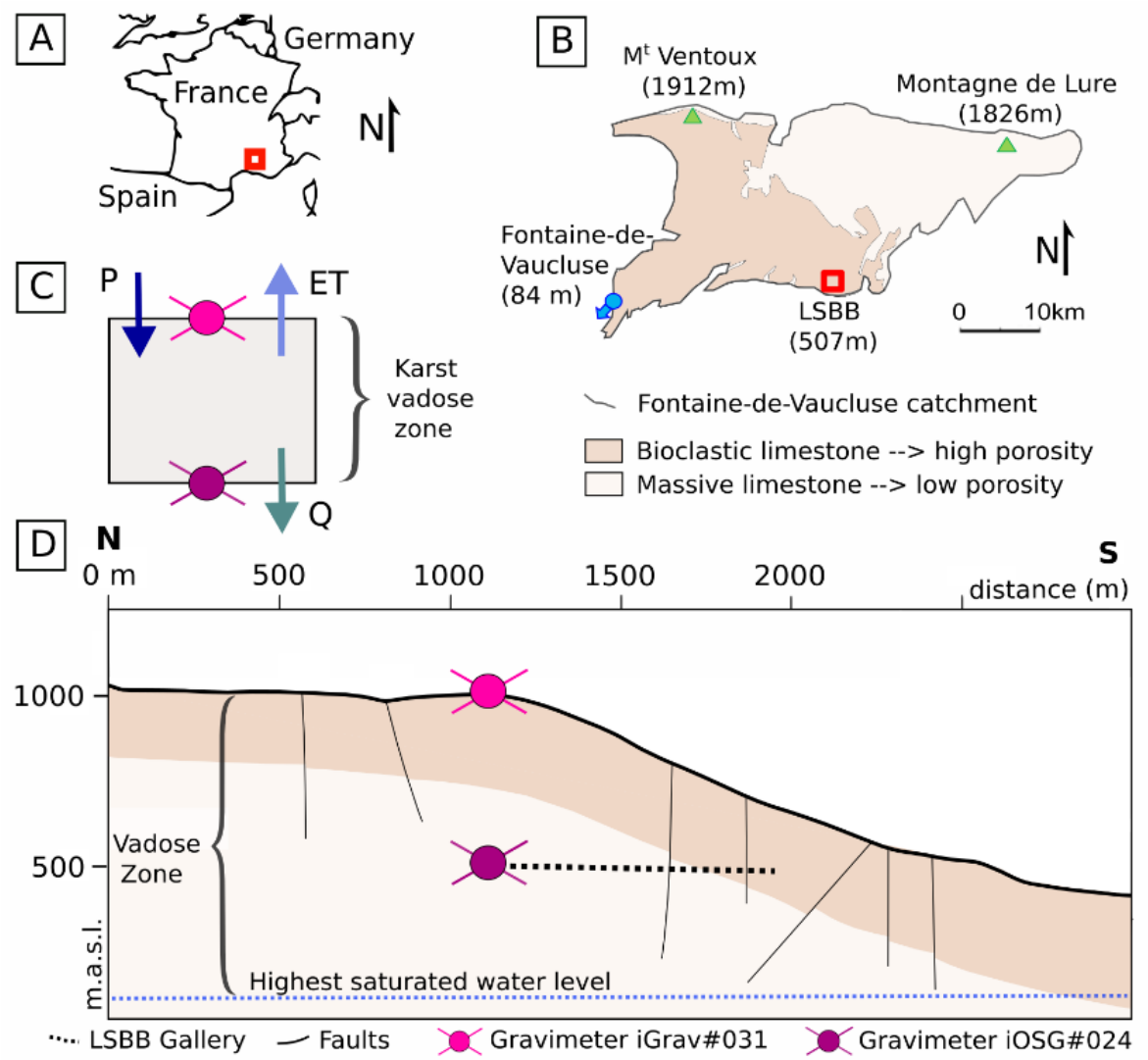

Figure 1. Site presentation: A/ Location map of the experimental site in France. B/ LSBB experimental site located in the Fontaine-de-Vaucluse catchment with a simplified geological context. C/ Simplified water balance of the system included between the two gravimeters where $\mathrm{P}$ is precipitation, ET is evapotranspiration, and Q is deep water discharge. Runoff is commonly neglected due to the very high permeability of the karst. D/ Simplified geological cross-section showing gravimeter locations and the influence cone of $90 \%$ of gravity signal. 
The climate is Mediterranean with hot dry summers; most rainfall occurs during spring and autumn. Between 2003 and 2015, average annual rainfall was $909 \mathrm{~mm}$ and ranged between 407 and $1405 \mathrm{~mm}$. Average annual temperature over the same period was $12.9^{\circ} \mathrm{C}$. Runoff is null at the scale of the massif due to the high karst permeability. No streams are present in the study area. Vegetation cover in the study area is primarily forest, dominated by Holm oaks on the southern slope [Carrière et al. 2017] and white oaks and Montpelier maples on the plateau.

\subsection{Superconducting gravimeter}

The LSBB is a unique site in the world for hydrogravimetric research because it is the only place to date where two superconducting gravimeters (SG) are installed in vertical alignment. This configuration allows us to study hourly mass changes in the area between the two gravimeters using the surface-to-depth approach developed by Jacob et al. [2009] and Champollion et al. [2018]. The SG iOSG\#024 [Boy et al. 2020] was installed in 2015 at a depth of $512 \mathrm{~m}$ (507 m.a.s.1.) and the SG iGrav\#031, installed at 1019 m.a.s.l., has been operational only since 2020. Both devices collect continuous data at the minute time step (iGrav\#031 and iOSG\#024). The instrumental drift of each gravimeter is corrected using repeated measurements of absolute gravity. In this paper, we only explore the surface-to-depth residual signal obtained by subtracting the deep SG signal from the surface SG signal. Residuals from single gravimeters are presented as supplementary material (S1). This simple difference makes it possible to circumvent the usual processing needed to eliminate all large-scale effects (e.g. tide, polar motion) while obtaining a signal with very low residual noise. This noise cancellation has already been demonstrated on laterally separated gravimeters (Kennedy et al. 2014; Goto et al. 2021). Compared to single gravity measurements, the sensitivity of differential gravity is modified by: i) removing common largescale effects; ii) enhancing the signal to noise ratio; iii) the sensitive volume is smaller than a single gravimeter (focused on the zone between both SG); iv) the sensitive volume extend laterally. Indeed, this vertical configuration offers a greater sensitivity on the sides of the device compared to a single gravimeter (Cooke 2020; Supplementary Information S2). The lateral sensitivity combined with the reduced common noise is a great advantage for studying near surface processes such as evapotranspiration.

We calculated the Daily Change in Gravity (DCG) by subtracting the signal average between $0 \mathrm{~h}$ and 5 h on day "d" from the same average on the next day "d+1" (Fig. 2B). Standard deviations were calculated each day over the same hourly period and then summed by pair of days to represent error bars in Figure 3b. During rain-free periods, the DCG consists mostly of signals from the lower (Q) and upper (ET) outlets of the karst system (Fig. 1C). Consequently, we subtract the gravitational attraction caused by changes in groundwater storage due to discharge at Fontaine-deVaucluse (Q) from DCG and compare the result to ET. Downward flow Q is expressed in mm by dividing the flow at the outlet of the Fontaine-de-Vaucluse spring by the surface of the entire hydrosystem $\left(1200 \mathrm{~km}^{2}\right)$. Surface-to-depth residuals can be expressed in $\mathrm{mm}$ by dividing acceleration (initially in $\mathrm{nm} / \mathrm{s}^{2}$ ) by the sum of absolute Bouguer constant for LSBB site (Kumar et al. 2021). They found $-0.34 \mathrm{~nm} / \mathrm{s}^{2} \cdot \mathrm{mm}^{-1}$ for the deep gravimeter and $0.39 \mathrm{~nm} / \mathrm{s}^{2} \cdot \mathrm{mm}^{-1}$ for the 
surface gravimeter. This double application of Bouguer's constant is equivalent to dividing the gradiometer signal by two in order to cancel the double detection of mass variations between the two gravimeters. As soil water is not spatially and temporally homogeneous, one can expect temporal changes of the Bouguer constant due to the precipitation patterns and the heterogeneity of the vegetation. Estimating a variable Bouguer coefficient in such complex medium as karst cannot be done from gravity data alone and numerical modeling including eco-physiological processes are needed.

\subsection{Evapotranspiration modeling}

The SimpKcET model was developed by Ollivier et al. [2021] to quantify ET over large karst areas. It was coupled to the KaRaMel model, which simulates water flow within karst systems [Ollivier et al. 2020], to improve the simulation of karst aquifer processes. SimpKcET was adapted from the FAO56 model [Allen et al. 1998] by considering parameterizations of soil and plant water transfers adapted to the particularities of karst surface layers (strongly heterogeneous with large amounts of coarse elements). SimpKcET uses the vegetation fraction cover derived from remote sensing data to force the evolution of plant transpiration from reference evapotranspiration inputs and a simple description of daily soil water balance including its impact on vegetation water stress. MODIS data was used to derive vegetation fraction cover at $1 \mathrm{~km}$ spatial resolution (calculated from the MODIS EVI). Meteorological inputs, such as precipitation and reference evapotranspiration, were obtained from SAFRAN reanalysis at a spatial resolution of $8 \mathrm{~km}$ [Vidal et al. 2010]. SimpKcET was favorably evaluated over three (3) flux towers on two (2) typical Mediterranean forested fields and one crop field in southeastern France [Ollivier et al. 2021]. In this paper, we used SimpKcET to model the evapotranspiration that was compared to the gravity data. ET was extracted from the 15 pixels covering the area $2 \mathrm{~km}$ around both SGs. These 15 pixels were used to evaluate ET (average) together with the ET variability.

\section{Results}

The surface-to-depth gravity residuals reveal a low-noise time series (Fig. 2A). Two phases can be clearly identified on the time series: i) gravity signal growth related to rainfall that increases the system mass between the two SGs, ii) signal decrease related to water loss from the system (ET and Q). Throughout the gravity time series, we notice several spikes, which are not related to hydrological processes but mainly to earthquakes and explosions due to the excavation of a new gallery within the LSBB.

During winter and spring, the residual time series is jagged because aquifer recharge occurs during this period. In fact, signal increases are synchronous with rainfall and increased flow at Fontainede-Vaucluse. During the summer, we observe a prolonged gravity signal decrease, which is linked to ET and Q processes. We can observe a consistency between, on the one hand, the slope reduction of the gravity time series and, on the other hand, the decrease of ET and Q related to the beginning of drought. At the daily time step, we can clearly see that the signal decreases in a step-wise pattern due to ET, as described by Van Camp et al. [2016] on the gravity signal or as other authors describe 
on piezometry [e.g. Healy and Cook 2002; Carlson Mazur et al. 2014] and the soil humidity time series [e.g. Nachabe et al. 2005; Jackisch et al. 2020]. The gravity signal drops during the day as a result of water loss in the system due to ET whereas the signal is more stable during the night (Fig. 2B). In fall, gravity time series becomes jagged again due to the beginning of seasonal rainfall and a new recharge period.

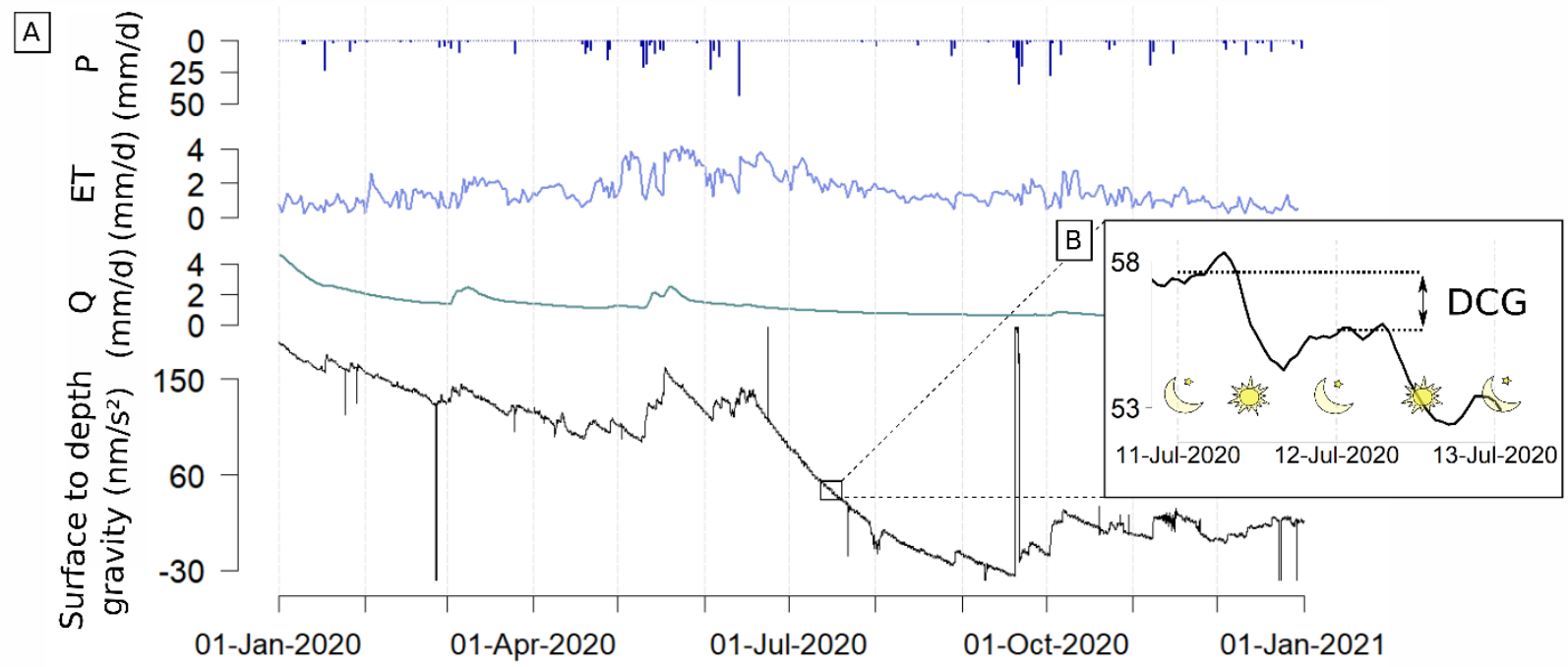

Figure 2. A/ Time series during the year 2020 for: precipitation (P); evapotranspiration (ET) calculated with the SimpKcET model [Ollivier et al. 2020] where gray lines are individual pixel time series and the sky blue line is the mean value calculated using 15 pixels within $2 \mathrm{~km}$ of the superconducting gravimeters; daily Fontaine-de-Vaucluse (FdV) discharge (Q) calculated in $\mathrm{mm} / \mathrm{d}$ by dividing discharge (in $\mathrm{m}^{3} / \mathrm{d}$ ) by surface of FdV catchment $\left(1200 \mathrm{~km}^{2}\right)$; and temporal dynamics of the surface-to-depth gravimetry. B/ two-day close-up on temporal dynamics of the surface-to-depth residuals to show how daily change in gravimetry (DCG) is determined.

\section{Interpretation and discussion}

The dataset allowed us to directly relate the gravity signal to ET. We exploited the unique configuration of two vertically spaced superconducting gravimeters to explore surface-to-depth gravity differences. We studied the June to September 2020 period in detail as it is a period of increased ET and low rainfall. Under these favorable conditions, we were able to relate a) mass changes measured by gravimeters minus water discharge $(\mathrm{Q})$ measured at the karst system outlet to b) ET modeled using the SimpKcET model [Ollivier et al. 2021].

Figure 3B shows strong Pearson (0.73) and Spearman (0.71) correlations between ET and DCG $-\mathrm{Q}$. These relations are broadly significant ( $\mathrm{p}$-values $<4.10^{-10}$ and $9.10^{-9}$, respectively). The small bias $(0.55 \mathrm{~mm})$ highlight a slight underestimate of modeled ET. It can be seen that the Q 
signal is fairly constant over the summer 2020 period (Fig. 2) because it shapes an extremely low gradual decay. As a result, the DCG signal can be primarily attributed to daily ET.

Our approach cannot be used for situations such as: i) rainy periods because water inflow into the system and related fast flows create a signal that dominates ET, ii) atmospheric conditions such as storms and periods of high or low pressure, iii) earthquakes, iv) explosions related to tunnel excavation within the LSBB. Because of these disturbances, 40 days indicated by the red areas (Fig. 3A) were removed from the analysis.

On the zoom of surface-to-depth residuals (Fig. 2B) it can be seen that the gravity signal rises during the afternoon. The rise is also seen in the stacked data of Van Camp et al. [2016]. We assume this phenomenon to be related to the change in lower atmosphere conditions (pressure, temperature, humidity) during the afternoon. Indeed, the water evapotranspired during the day is removed by the convective exchange between the boundary layer and the free troposphere and trapped in the atmospheric boundary layer at the end of the day when convection vanished [Champollion et al. 2005]. Despite this misunderstood phenomenon, our analysis remains largely unaffected because we calculate DCG over two consecutive days at fixed times.

A

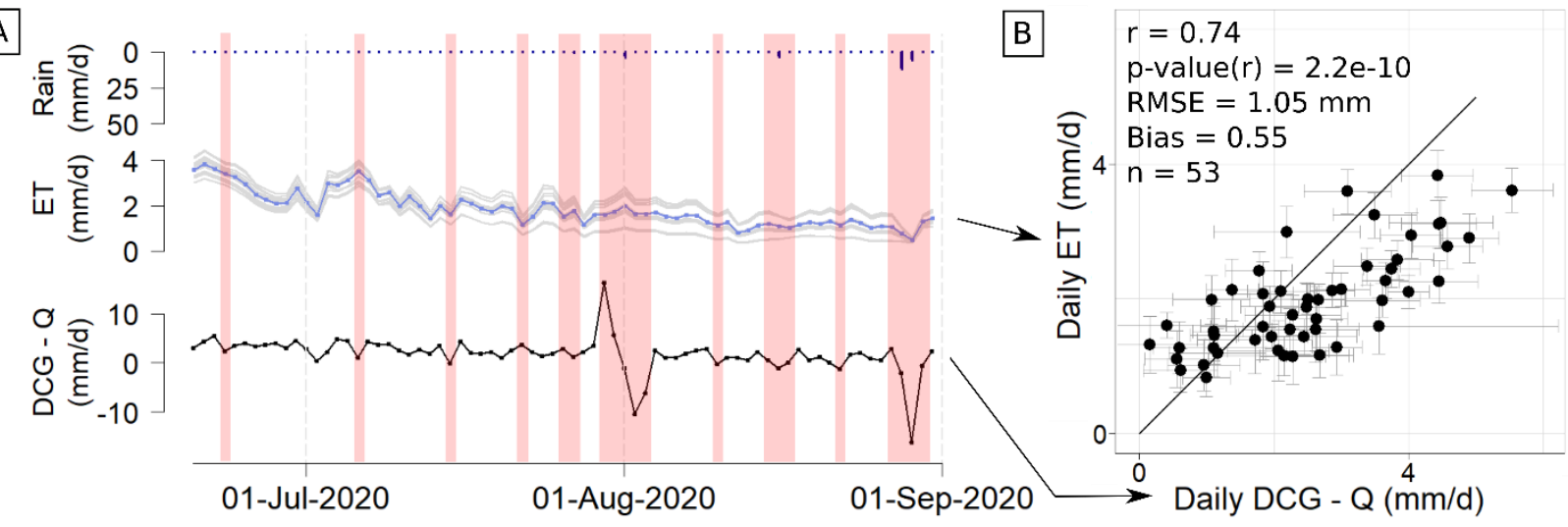

Figure 3. Comparison of measured surface-to-depth gravimetry signal minus discharge (Q) measured at the Fontaine-de-Vaucluse spring with the modeled evapotranspiration (ET). A/ Temporal graphs. The red areas are periods excluded from the analysis because they are affected by various phenomena (earthquake, storm, rain and explosion). ET gray lines are individual pixel time series and the sky blue line is the mean value calculated within 15 pixels surrounding the superconducting gravimeters. The cumulated daily flow at Fontaine-de-Vaucluse was divided by the surface of hydrosystem $(1200 \mathrm{~km})$ to express discharge in $\mathrm{mm} / \mathrm{d}$. P is precipitation. $\mathrm{B} /$ Correlation between daily ET modeled and daily DCG - Q measured (r: Pearson correlation;

RMSE: root mean square error; $n$ : number of value). 


\section{Conclusions}

Determining daily ET by gravimetry is a major challenge that approaches the technological and signal processing limits of current gravimetry. Indeed, the objective is to detect daily variations that are sometimes less than $1 \mathrm{~nm} / \mathrm{s}^{2}$. To reach conclusive results, we have enumerated the conditions that make it possible to highlight the expected signal:

i) we selected days without rain during a summer period (June - September) when the ET signal was quite strong $(>1 \mathrm{~mm} / \mathrm{j})$.

ii) we used data from two gravimeters to subtract the signals with two consequences: suppression of undesirable large-scale effects (e.g., tide) and maximization of the gravity signal between the two SGs.

Considering these last points, we were able to highlight that, in the studied system (Fig. 1B), the daily water outflow by ET (from SimpKcET model) agreed reasonably well with daily mass change (from residuals gradients) subtracted from the discharge at the outlet of the system (from Fontaine-de-Vaucluse discharge). The water stock dynamic is a key variable in hydrology that is generally difficult to quantify and the surface to depth superconducting gravimetry can quantify this key parameter with a precision around $1 \mathrm{~nm} / \mathrm{s}^{2}$. The high accuracy allows to indirectly estimate the ET at daily time step via the water stock variation.

This work is at the interface between geophysics and hydrology. The results open new perspectives for both communities:

i) in gravimetry, which can now consider ET to be a process that can significantly create noise in the gravity signal at the subdaily time step, according to the results of this study

ii) in hydrology, which can consider gravimetry as a new method for approaching ET, with four main advantages: a large integration volume, a stable influence area over time (unlike Eddy covariance or scintillometry), and minimal required maintenance. However, the installation of a SG is sometimes more cumbersome than a flux tower (depending on the vegetation cover) and requires a main power supply.

Our results encourage collaborative work among hydrologists and geophysicists to improve signal processing in order to deduce ET from the gravimetric signal at experimental sites equipped with a single SG. To achieve this goal, it may be useful to implement additional measurements to improve signal processing (e.g. full parameter meteorological station, sap flow sensors on trees). We can also expect that in the future decades gravimeters pairs (or even network of gravimeters) will be deployed at multiple experimental sites with one SG at the surface and the other deep inside a borehole. Finally, it will be interesting to make a direct comparison between gravity measurements and ET measurements (e.g. eddy-covariance, scintillometry). 


\section{Acknowledgments, Samples, and Data}

- The authors would like to express their gratitude to CIRAME and to all the LSBB team. Data used in this study were collected by the SNO KARST and $\mathrm{H}^{+}$. SNO KARST and $\mathrm{H}^{+}$are part of the OZCAR Research Infrastructure, which is supported by the French Ministry of Research, French Research Institutions and Universities. SimpKcET was developed within the framework of the PITEAS project and the TRISHNA project, which received financial support from CNES. The superconducting gravimeter iGrav\#031 was funded by the Equipex CRITEX project and the superconducting gravimeter iOSG\#024 was funded by the Equipex MIGA project.

\section{Open Research}

- Superconducting gravimetry data is accessible using the following links: surface SG iGrav\#031 (http://igets.u-strasbg.fr/SG/ru031/Level1/) and deep SG iOSG\#024 (http://igets.u-strasbg.fr/SG/ru024/Level1/)

\section{References}

Allen, R. G., Pereira, L. S., Raes, D., Smith, M., \& others. (1998). Crop evapotranspirationGuidelines for computing crop water requirements-FAO Irrigation and drainage paper 56. FAO, Rome, 300(9). Retrieved from http://www.fao.org/docrep/X0490E/X0490E00.htm

Boy, J.-P., Rosat, S., Hinderer, J., Gaffet, S., \& Littel, F. (2020). Superconducting Gravimeter Data from Rustrel (LSBB)-Level 1. https://doi.org/10.5880/igets.ru.I1.001

Carlson Mazur, M. L., Wiley, M. J., \& Wilcox, D. A. (2014). Estimating evapotranspiration and groundwater flow from water-table fluctuations for a general wetland scenario. Ecohydrology, 7(2), 378-390.

Carrière, S. D., Chalikakis, K., Danquigny, C., Davi, H., Mazzilli, N., Ollivier, C., \& Emblanch, C. (2016). The role of porous matrix in water flow regulation within a karst unsaturated zone: an integrated hydrogeophysical approach. Hydrogeology Journal, 24(7), 1905-1918.

Carrière, S. D., Danquigny, C., Davi, H., Chalikakis, K., Ollivier, C., Martin-StPaul, N. K., \& Emblanch, C. (2017). Process-Based Vegetation Models Improve Karst Recharge Simulation Under Mediterranean Forest. In EuroKarst 2016, Neuchâtel (pp. 109-116). Springer.

Chaffaut, Q., Hinderer, J., Masson, F., Viville, D., Pasquet, S., Boy, J., et al. (2021). New insights on water storage dynamics in a mountainous catchment from superconducting gravimetry. Geophysical Journal International. 
Champollion, C., Masson, F., Bouin, M.-N., Walpersdorf, A., Doerflinger, E., Bock, O., \& Van Baelen, J. (2005). GPS water vapour tomography: preliminary results from the ESCOMPTE field experiment. Atmospheric Research, 74(1-4), 253-274.

Champollion, C., Deville, S., Chery, J., Doerflinger, E., Moigne, N. L., Bayer, R., et al. (2018). Estimating epikarst water storage by time-lapse surface-to-depth gravity measurements. Hydrology and Earth System Sciences, 22(7), 3825-3839.

Cooke, A.-K. (2020). Characterisation of a new mobile absolute quantum gravimeter : application in groundwater storage monitoring. Retrieved from http://www.theses.fr/2020MONTG043/document

Deville, S., Jacob, T., Chéry, J., \& Champollion, C. (2013). On the impact of topography and building mask on time varying gravity due to local hydrology. Geophysical Journal International, 192(1), 82-93. https://doi.org/10.1093/gji/ggs007

Fisher, J. B. (2014). Land-Atmosphere Interactions, Evapotranspiration.

Fisher, J. B., Melton, F., Middleton, E., Hain, C., Anderson, M., Allen, R., et al. (2017). The future of evapotranspiration: Global requirements for ecosystem functioning, carbon and climate feedbacks, agricultural management, and water resources. Water Resources Research, 53(4), 2618-2626.

Fores, B., Champollion, C., Mainsant, G., Albaric, J., \& Fort, A. (2018). Monitoring saturation changes with ambient seismic noise and gravimetry in a karst environment. Vadose Zone Journal, 17(1).

Garry, B. (2007). Etude des processus d'écoulements de la zone non saturée pour la modelisation des acquifères karstiques. Expérimentation hydrodynamique et hydrochimique sur les sites du Laboratoire Souterrain à Bas Bruit (LSBB) de Rustrel et de Fontaine de Vaucluse. Université d'Avignon et des Pays de Vaucluse, Avignon.

Goto, H., Sugihara, M., Nishi, Y., \& Ikeda, H. (2021). Simultaneous gravity measurements using two superconducting gravimeters to observe temporal gravity changes below the $\mathrm{nm} \mathrm{s}-2$ level: ocean tide loading differences at different distances from the coast. Geophysical Journal International, 227(3), 1591-1601.

Guglielmi, Y. (2010). Carbonate reservoirs - The Rustrel-Fontaine de Vaucluse LSBB: a unique facility for deep carbonate reservoir. Presented at the I-Dust 2010.

Hartmann, T., \& Wenzel, H. (1995). The HW95 tidal potential catalogue. Geophysical Research Letters, 22(24), 3553-3556.

Healy, R. W., \& Cook, P. G. (2002). Using groundwater levels to estimate recharge. Hydrogeology Journal, 10(1), 91-109.

Hector, B., Hinderer, J., Séguis, L., Boy, J.-P., Calvo, M., Descloitres, M., et al. (2014). Hydrogravimetry in West-Africa: first results from the Djougou (Benin) superconducting gravimeter. Journal of Geodynamics, 80, 34-49. 
Jackisch, C., Knoblauch, S., Blume, T., Zehe, E., \& Hassler, S. K. (2020). Estimates of tree root water uptake from soil moisture profile dynamics. Biogeosciences, 17(22), 5787-5808.

Jacob, T., Chery, J., Bayer, R., Le Moigne, N., Boy, J.-P., Vernant, P., \& Boudin, F. (2009). Timelapse surface to depth gravity measurements on a karst system reveal the dominant role of the epikarst as a water storage entity. Geophysical Journal International, 177(2), 347-360. https://doi.org/10.1111/i.1365-246X.2009.04118.x

Kennedy, J., Ferré, T. P., Güntner, A., Abe, M., \& Creutzfeldt, B. (2014). Direct measurement of subsurface mass change using the variable baseline gravity gradient method. Geophysical Research Letters, 41(8), 2827-2834.

Kumar, S., Rosat, S., Hinderer, J., \& Mouyen, M. (2021). Groundwater monitoring and characterization by a vertical dipole of superconducting gravimeters in a karst aquifer, France (pp. 889-893). Presented at the First International Meeting for Applied Geoscience \& Energy, Society of Exploration Geophysicists.

Léonide, P., Fournier, F., Reijmer, J. J. G., Vonhof, H., Borgomano, J., Dijk, J., et al. (2014). Diagenetic patterns and pore space distribution along a platform to outer-shelf transect (Urgonian limestone, Barremian-Aptian, SE France). Sedimentary Geology, 306(0), 1-23. https://doi.org/10.1016/i.sedgeo.2014.03.001

Lesparre, N., Boudin, F., Champollion, C., Chéry, J., Danquigny, C., Seat, H. C., et al. (2017). New insights on fractures deformation from tiltmeter data measured inside the Fontaine de Vaucluse karst system. Geophysical Journal International, 208(3), 1389-1402. https://doi.org/10.1093/gji/ggw446

Long, D., Longuevergne, L., \& Scanlon, B. R. (2014). Uncertainty in evapotranspiration from land surface modeling, remote sensing, and GRACE satellites. Water Resources Research, 50(2), 1131-1151.

Masse, J. P. (1969). Contribution a l'étude de l'Urgonien (Barrémien - Bédoulien) des Monts de vaucluse et du Luberon (p. 59). Orléan: Bureau de Recherches Géologiques et Minières.

Masse, J.-P., \& Fenerci-Masse, M. (2011). Drowning discontinuities and stratigraphic correlation in platform carbonates. The late Barremian-early Aptian record of southeast France. Cretaceous Research, 32(6), 659-684. https://doi.org/10.1016/i.cretres.2011.04.003

Mazzilli, N., Chalikakis, K., Carrière, S. D., \& Legchenko, A. (2020). Surface Nuclear Magnetic Resonance Monitoring Reveals Karst Unsaturated Zone Recharge Dynamics during a Rain Event. Water, 12(11), 3183.

Mu, Q., Zhao, M., \& Running, S. W. (2011). Improvements to a MODIS global terrestrial evapotranspiration algorithm. Remote Sensing of Environment, 115(8), 1781-1800.

Müller, J., \& Bolte, A. (2009). The use of lysimeters in forest hydrology research in north-east Germany. Landbauforschung (VTI Agric. For. Res.), 59, 1-10. 
Nachabe, M., Shah, N., Ross, M., \& Vomacka, J. (2005). Evapotranspiration of two vegetation covers in a shallow water table environment. Soil Science Society of America Journal, 69(2), 492-499.

Oki, T., \& Kanae, S. (2006). Global hydrological cycles and world water resources. Science, 313(5790), 1068-1072.

Ollivier, C, Olioso, A., Carrière, S., Boulet, G., Chalikakis, K., Chanzy, A., et al. (2021). An evapotranspiration model driven by remote sensing data for assessing groundwater resource in karst watershed. Science of The Total Environment, 146706.

Ollivier, Chloé, Mazzilli, N., Olioso, A., Chalikakis, K., Carrière, S. D., Danquigny, C., \& Emblanch, C. (2020). Karst recharge-discharge semi distributed model to assess spatial variability of flows. Science of the Total Environment, 703, 134368.

Pan, Y., Zhang, C., Gong, H., Yeh, P. J., Shen, Y., Guo, Y., et al. (2017). Detection of human-induced evapotranspiration using GRACE satellite observations in the Haihe River basin of China. Geophysical Research Letters, 44(1), 190-199.

Pascolini-Campbell, M., Reager, J. T., Chandanpurkar, H. A., \& Rodell, M. (2021). A 10 per cent increase in global land evapotranspiration from 2003 to 2019. Nature, 593(7860), 543-547. https://doi.org/10.1038/s41586-021-03503-5

Rodell, M., Famiglietti, J., Chen, J., Seneviratne, S., Viterbo, P., Holl, S., \& Wilson, C. (2004). Basin scale estimates of evapotranspiration using GRACE and other observations. Geophysical Research Letters, 31(20).

Van Camp, M., Vanclooster, M., Crommen, O., Petermans, T., Verbeeck, K., Meurers, B., et al. (2006). Hydrogeological investigations at the Membach station, Belgium, and application to correct long periodic gravity variations. Journal of Geophysical Research: Solid Earth, 111(B10).

Van Camp, M., de Viron, O., Pajot-Métivier, G., Casenave, F., Watlet, A., Dassargues, A., \& Vanclooster, M. (2016). Direct measurement of evapotranspiration from a forest using a superconducting gravimeter: evapotranspiration and gravity. Geophysical Research Letters, 43(19), 10,225-10,231. https://doi.org/10.1002/2016GL070534

Verstraeten, W. W., Veroustraete, F., \& Feyen, J. (2008). Assessment of evapotranspiration and soil moisture content across different scales of observation. Sensors, 8(1), 70-117.

Vidal, J.-P., Martin, E., Franchistéguy, L., Baillon, M., \& Soubeyroux, J.-M. (2010). A 50-year highresolution atmospheric reanalysis over France with the Safran system. International Journal of Climatology, 30(11), 1627-1644. https://doi.org/10.1002/joc.2003

Wenzel, H.-G. (1996). The nanogal software: Earth tide data processing package ETERNA 3.30. Bull. Inf. Marées Terrestres, 124, 9425-9439.

Zhang, S., Wen, X., Wang, J., Yu, G., \& Sun, X. (2010). The use of stable isotopes to partition evapotranspiration fluxes into evaporation and transpiration. Acta Ecologica Sinica, 30(4), 201-209. 